See Article page 295.

\section{Commentary: A unified chain of command for organized team performance}

\author{
Fumiya Yoneyama, MD, and Iki Adachi, MD
}

In this issue of the Journal, Greene and colleagues ${ }^{1}$ describe a case of a neonatal patient with a large right coronary artery fistula to the right ventricle that had been successfully treated with the "hybrid" approach. The treatment journey started with fetal diagnosis, followed by an emergent cesarean section and intubation immediately after birth. Because of the ongoing escalation of inotropic support, the patient was taken to the catheterization laboratory to confirm the diagnosis as well as for hemodynamic assessment. In the laboratory, the authors came up with the idea of leaving a $0.014^{\prime \prime}$ guide wire in the fistulous tract from the femoral artery to help identify the fistula in the subsequent surgical repair. The patient was then transferred to the operative room.

The operation was conducted without much difficulty, leading to excellent early and mid-term outcomes. This type of operation can be very challenging both anatomically and physiologically. ${ }^{2,3}$ In particular, the presence of substantial coronary steal makes cardiopulmonary bypass management complicated in terms of maintenance of systemic perfusion and myocardial protection. The success of their multidisciplinary approach would be a reflection of each individual specialty, including cardiology, intensive care, and surgery, fulfilling its own role at the highest standard. It is incredible to see how smooth the patient's clinical journey

From the Division of Congenital Heart Surgery, Michael E. DeBakey Department of Surgery, Texas Children's Hospital, Baylor College of Medicine, Houston, Tex.

Disclosures: Dr Adachi serves as a consultant/proctor for Berlin Heart, Medtronic, Jarvik, BiVACOR, and Sony-Olympus Medical Solutions. Dr Yoneyama has reported no conflicts of interest.

The Journal policy requires editors and reviewers to disclose conflicts of interest and to decline handling or reviewing manuscripts for which they may have a conflict of interest. The editors and reviewers of this article have no conflicts of interest.

Received for publication Aug 11, 2020; revisions received Aug 11, 2020; accepted for publication Aug 13, 2020; available ahead of print Aug 15, 2020.

Address for reprints: Iki Adachi, MD, Michael E. DeBakey Department of Surgery, Baylor College of Medicine, 6651 Main St, Houston, TX 77030 (E-mail: iadachi@bcm.edu).

JTCVS Techniques 2020;3:298

2666-2507

Copyright (c) 2020 The Authors. Published by Elsevier Inc. on behalf of The American Association for Thoracic Surgery. This is an open access article under the CC BY-NCND license (http://creativecommons.org/licenses/by-nc-nd/4.0/).

https://doi.org/10.1016/j.xjtc.2020.08.030
Check for updates

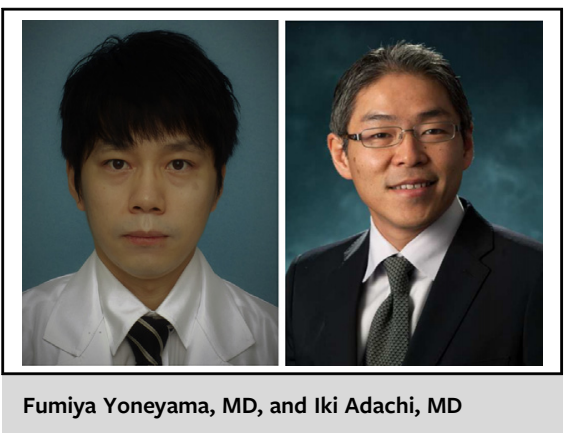

CENTRAL MESSAGE

A team cannot function properly

without a commander. The sur-

geon must play a key role to

make the team approach

successful.

was despite the expected challenges. Such clinical capabilities is one reason why the authors' institution is so well respected in our field.

Also of note is what ultimately makes the authors' multidisciplinary approach successful. Having good clinicians in each specialty does not necessarily guarantee adequate performance of the combined effort, because a team cannot function properly without a commander. It is the unified chain of command that makes individual actions aligned toward the ultimate goal. This is very true when the mission is complex. Even though the leadership role within the authors' team is not specified in the report, there is little doubt that the surgeon must have played a key role. In other words, it would not be an overestimation to assume that the superb surgical leadership would be what made their team approach ultimately successful. This may be the most critical element of their case report, from which our surgical community can learn beyond just the technical pitfalls of coronary fistula management.

\section{References}

1. Greene C, Friedman K, Callahan R, Baird C. Case report: hybrid approach to neonatal repair of large symptomatic congenital coronary artery fistula. $J$ Thorac Cardiovasc Surg Tech. 2020;3:295-7.

2. Yim D, Yong MS, d'Udekem Y, Brizard CP, Konstantinov IE. Early surgical repair of the coronary artery fistulae in children: 30 years of experience. Ann Thorac Surg. 2015;100:188-94.

3. Manoly I, Mahadevan VS, Hoschtitzky JA. Hybrid approach to closure of an acquired coronary-cameral fistula. Ann Thorac Surg. 2014;98:e59-61. 